\title{
Emerging Roles of Kisspeptin in Sexual and Emotional Brain Processing
}

\author{
Alexander N. Comninos ${ }^{a, b}$ Waljit S. Dhillo ${ }^{a}$ \\ ${ }^{a}$ Section of Endocrinology and Investigative Medicine, Imperial College London, and ${ }^{b}$ Department of \\ Endocrinology, Imperial College Healthcare NHS Trust, London, UK
}

\section{Keywords}

Kisspeptin · Kiss1 - Kiss1r - Gpr54 · Amygdala - Reproductive behaviour - Sexual behaviour - Sexual arousal - Behaviour . Limbic system · Mood

\begin{abstract}
The emergence of kisspeptin as a crucial regulator of the hypothalamo-pituitary-gonadal (HPG) axis over the last 14 years has answered many questions as to the control of reproductive hormone secretion from the hypothalamus. More recently, the role of kisspeptin outside the HPG axis has received increasing attention in the hope of delineating the pathways linking various sensory and social behaviours to reproduction. These studies, in a range of species from zebrafish to humans, have identified a role for kisspeptin in behavioural networks related to reproduction including olfaction, audition, fear, anxiety, mood, and sexual arousal. The available evidence suggests that extrahypothalamic kisspeptin signalling encourages positive aspects of emotional and sexual brain processing in a presumed drive towards reproduction and ultimately maintenance of the species at a population level. In this review, we examine these studies, which collectively propose that kisspeptin may integrate sexual and emotional brain processing with the control of the HPG axis.

(c) 2017 S. Karger AG, Basel
\end{abstract}

(C) 2017 S. Karger AG, Basel

\section{Introduction}

Reproduction is required for survival of all species. The success of reproduction, however, depends on a multitude of ingredients encompassing anatomical, metabolic, hormonal, and psychological factors. These factors interplay to achieve reproductive success, but in some species such as humans, reproduction is not always the desired outcome. In humans, sexual and emotional brain processing can provide sought-after reward and satisfaction without the need for reproduction.

While we classically think of testosterone as the main reproductive hormone governing sexual brain processing to maintain libido, significant evidence suggests that other factors are also involved. Kisspeptin describes a family of peptide hormones of varying amino acid length cleaved from the product of the KISS1 gene in primates (including humans) and the Kiss1 gene in non-primates. The kisspeptin peptides share a common carboxy-terminal sequence necessary for their action on kisspeptin receptors (encoded by KISS1R/Kiss1r). Although initially identified for their role in metastasis suppression in 1996 [1], in 2003, two seminal papers identified the critical importance of kisspeptin signalling in reproduction, demonstrating that absence of KISS1R results in failure of puberty and subsequent infertility $[2,3]$. A

\section{KARGER}

E-Mail karger@karger.com

www.karger.com/nen 
similar failure of puberty has more recently been observed in the absence of KISS1 [4]. Conversely, activating mutations of KISS1 and KISS1R lead to central precocious puberty $[5,6]$. Therefore, kisspeptin and its cognate receptor are obligate for successful reproduction. These findings have spawned a plethora of studies that place kisspeptin signalling at the apex of the hypothalamo-pituitary-gonadal (HPG) axis, and examined the various factors governing these signals and their resultant effects on the downstream gonadotrophins and gonadal sex steroids [7].

Kisspeptin is secreted by kisspeptin neurones within the hypothalamus and activates kisspeptin receptors upon gonadotrophin-releasing hormone $(\mathrm{GnRH})$ neurones resulting in GnRH release into the local hypophyseal-portal circulation. This GnRH arrives at the gonadotrophs of the anterior pituitary, and stimulates the release of the gonadotrophins (luteinising hormone $[\mathrm{LH}]$ and follicle stimulating hormone [FSH]) into the systemic circulation. The gonadotrophins then stimulate the gonads to release testosterone in males, and oestradiol as well as progesterone in females. However, kisspeptin signalling is not limited to the hypothalamus but also occurs in other extrahypothalamic brain regions. It is these locations for kisspeptin signalling that gave the first clues for kisspeptin's role in sexual and emotional processing.

In this review, we examine the literature to date supporting a key role for kisspeptin in sexual and emotional brain processing in various species. We identified the relevant publications by a series of PubMed searches, employing relevant keywords either alone or in combination: Kisspeptin, Kiss1, Kiss1r, Gpr54, Reproduction, Sex, Emotion, Behaviour, Olfaction, Audition, Fear, Mood, Anxiety. Relevant data were subsequently extracted from the identified publications, and secondary data sources identified therein. To ensure the inclusion of the most current data available, searches were performed up until the 8th of August 2017.

\section{Kisspeptin Signalling outside the Hypothalamus}

Extensive work has identified Kiss 1 and its cognate receptor expression within the rodent hypothalamus, predominantly within the arcuate nucleus (ARC), anteroventral periventricular nucleus (AVPV), preoptic periventricular nucleus, and preoptic area, which are all areas implicated in the modulation of $\mathrm{GnRH}$ secretion as part of the HPG axis [8-15]. In primates (including humans), hypothalamic KISS1 and KISS1R mRNA is predominant- ly located within the infundibular nucleus, preoptic area, and the rostral periventricular zone (RP3V) [16-20].

However, it is interesting to consider the sites of kisspeptin signalling expression outside the hypothalamus to glean clues as to functional roles for kisspeptin outside the HPG axis. Kisspeptin has been identified in the stria terminalis, amygdala, and thalamus using a polyclonal rabbit antibody to identify the terminal amino acid sequence of kisspeptin [10]. Kiss1 mRNA has also been identified in the rodent amygdala where its expression is positively modulated by gonadal sex steroids [21, 22]. Other brain regions demonstrating Kiss1r expression include the habenula, thalamus, hippocampus, and the olfactory system $[15,23,24]$. In humans, KISS1 and KISS1R mRNA has been identified outside the hypothalamus in the amygdala, caudate, cingulate, globus pallidus, hippocampus, medial and superior frontal gyrus, nucleus accumbens, parahippocampal gyrus, substantia nigra, putamen, and thalamus in varying degrees $[19,20]$.

Functional studies in rodents have shown that extrahypothalamic kisspeptin signalling can influence the HPG axis to modulate reproductive hormone secretion. Direct intra-amygdala injection of kisspeptin results in increased LH secretion, while conversely blocking endogenous amygdala kisspeptin signalling with a kisspeptin antagonist decreases both LH secretion and LH pulsatility [25], clearly demonstrating the influence of kisspeptin signalling outside the hypothalamus on the HPG axis.

Collectively, these data demonstrate an anatomical brain framework for kisspeptin signalling outside the hypothalamus extending to areas involved in emotions including sexual behaviour, fear, anxiety, mood, and olfaction. This is highlighted by the identification of kisspeptin and its cognate receptor in key limbic structures that orchestrate emotions including the amygdala, hippocampus, cingulate, and thalamus as well as paralimbic structures that feed into this system such as the accumbens, stria terminalis, putamen, and globus pallidus [26].

\section{Kisspeptin and Olfaction}

Olfactory stimuli initiate a wide range of social behaviours and emotions and are well established to play a crucial role in mammalian reproduction [27]. Recently, an anatomical framework for kisspeptin's role in olfaction has been identified in rodents involving the amygdala, which is a central structure in the olfactory system [24]. Using microinjections of retro- and anterograde tracers, neuronal connections were observed between the acces- 
sory olfactory bulb and kisspeptin neurones within the amygdala with these latter neurones also projecting via the stria terminalis to GnRH neurones in the preoptic area [24]. Furthermore, fluorescence immunochemistry revealed close appositions between these amygdala kisspeptin neurones and vasopressinergic and (tyrosine hydroxylase-positive) dopaminergic neurones [24], which both have established roles in social behaviours including affiliation, motivation, and reward [28, 29]. Interestingly, half of the olfactory mitral cells were inhibited by kisspeptin administration (as determined by electrophysiological studies), but the precise significance of this and the interactions with other cells of the olfactory system such as inhibitory granule cells remains to be determined [24]. It is feasible that the changes in kisspeptin expression in the amygdala during the oestrous cycle (peaking around the time of mating [21]) may contribute to the filtering of odour cues by the olfactory system at this crucial time, but this requires further study.

The earliest evidence for a role for kisspeptin signalling in olfactory reproductive behaviour came from a study examining the consequences of global Kiss1r knock-out in male mice [30]. Wild-type males spent $>70 \%$ of their time investigating (i.e., sniffing) female mice, but testosterone-replaced Kiss1r knock-out male mice did not investigate females preferentially over males, despite normal olfactory function confirmed by a hidden cookie test [30]. These findings provided an important indication for the role of the kisspeptin receptor in opposite-sex olfactory reproductive behaviour. Along these lines, selective activation of posterodorsal medial amygdala kisspeptin neurones (using DREADD technology [Designer Receptors Exclusively Activated by Designer Drugs]) increased the time spent by male mice investigating oestrous females [31]. However, this activation also resulted in increased duration spent socialising with a juvenile mouse, and so suggests that amygdala kisspeptin signalling may modulate not only opposite-sex preference but also juvenile odour preference. Whether the effects in this latter study are via kisspeptin secretion or other neurotransmitters released from kisspeptin neurones remains to be determined.

Studies employing opposite-sex urinary odours also provide evidence for the importance of kisspeptin signalling in olfactory-reproductive pathways in male as well as female rodents. Male wild-type mice exposed to oestrous female urine demonstrated significantly increased Fos expression in kisspeptin neurones in the RP3V (consisting of the AVPV and periventricular nucleus) of the hypothalamus compared to males exposed to male urine or

Emerging Roles of Kisspeptin in Sexual and Emotional Brain Processing control water [32]. Moreover, an even greater increase in RP3V kisspeptin neuronal Fos expression was observed in female wild-type mice exposed to male urinary odours (compared to female oestrous urine or control water) [32]. Consistent with this, a recent study in female rats (ovariectomised and implanted with preovulatory oestradiol levels) demonstrated increased AVPV and limbic (but not ARC) kisspeptin neuronal Fos expression following exposure to male-soiled bedding [33]. Furthermore, these female rats showed enhanced LH surges compared to female rats exposed to clean or female-soiled bedding, therefore providing functional relevance [33].

Taken together, these studies (summarised in Fig. 1) provide an anatomical and physiological framework for kisspeptins role in the integration of olfactory cues and social behaviours (via vasopressin and dopamine) with the HPG axis in both male and female rodents.

\section{Kisspeptin and Audition}

Another sensory modality associated with reproduction is audition. A recent study demonstrated that male mice typically emit song-like "ultrasonic vocalisations" (USVs) in response to females, which results in their subsequent approach. Furthermore, the presence of males USVs increased the number of subsequent offspring compared to the absence of USVs (by devocalisation) [34]. Interestingly, male USVs increased female kisspeptin neuronal activity (determined by pCREB expression [phosphorylation of Cyclic AMP Response Element Binding]) in the ARC (but not the AVPV), which correlated with duration of female searching behaviour for the speaker (i.e., the male) [34]. Together with data demonstrating kisspeptin receptor expression in the dorsal cochlear nucleus [23], this suggests a role for kisspeptin in auditory reproductive processing.

\section{Kisspeptin and Fear}

Fear is a cardinal emotion that can impair reproductive performance and therefore influence onward behaviours to protect against threats to the species. In several fish species, alarm substance (AS) is released by specialised epidermal cells when their skin is damaged by a predator. This AS release results in a fear reaction (such as erratic movement and freezing) in neighbouring fish which detect the AS using their sensitive chemoreceptors [35]. In this way, AS can also be used to evoke fear in fish 
behavioural studies [35]. In zebrafish, AS-evoked fear stimuli significantly reduces Kiss 1 and serotonin-related gene transcription (pet1 and slc6a4a), while intracranial kisspeptin administration suppresses AS-evoked fear responses (erratic movement and freezing) [36]. In subsequent studies, the authors observed that pharmacological blockade of serotonin receptors $\left(5-\mathrm{HT}_{1 \mathrm{~A}}\right.$ and $\left.5-\mathrm{HT}_{2}\right)$ removed this anxiolytic effect of kisspeptin [37] and that kisspeptin modulated the serotonergic system here primarily via glutamatergic neurotransmission [38]. Furthermore, selective inactivation of Kiss1 neurones (using kisspeptin conjugated to saporin) resulted in reduced Kiss1 immunoreactivity and Fos expression within the habenula and raphe (key structures in the fear response), which resulted in attenuated AS-evoked fear responses [36]. The role of kisspeptin in fear has as yet not been explored in other species, but these studies in zebrafish provide evidence that kisspeptin can attenuate fear responses via serotonergic pathways, a finding with implications for successful reproduction and conservation of the species.

\section{Kisspeptin and Mood}

The hypothalmo-pituitary-adrenal axis regulates adrenocorticotropin hormone and corticosteroid release in response to anxiety, an effect that does not appear to be influenced by peripheral kisspeptin administration in rodents [39] or humans [40]. However, stress-induced plasma corticosterone decreases kisspeptin signalling in the hypothalamus [41] providing evidence for an interplay between hormonal aspects of anxiety, stress, and the kisspeptin system.

The functional data regarding kisspeptin's role in anxiety is perhaps less clear. Intracerebroventricular kisspeptin injection in male rodents decreased time spent in the open arms of a maze, suggesting that kisspeptin administration increases anxiety [42]. By contrast, a more recent study observed that DREADD activation of medial amygdala kisspeptin neurones in male rodents increased time in the open arms of a maze suggesting a decrease in anxiety [31]. This latter study is in agreement with studies in zebrafish demonstrating anxiolytic effects of kisspeptin administration in a novel tank diving test designed to assess anxiety (increased top-to-bottom transitions), associated with enhanced 5-HT-related gene expression $[36,43]$. Therefore, these contrasting data propose a differential effect between global activation of central kisspeptin receptors via central kisspeptin administration in rodents and zebrafish, versus pure ac- tivation of medial amygdala kisspeptin neurones which may release kisspeptin as well as additional neurotransmitters. Further work is therefore required to clarify the role of kisspeptin signalling in anxiety across species.

Kisspeptin's modulation of the serotonergic system has also been explored in relation to mood (summarised in Fig. 1). During a forced swimming test in rodents designed to assess depressive behaviour, intracerebroventricular administration of kisspeptin dose-dependently reversed immobility, climbing, and swimming times suggesting antidepressant-like effects which were attenuated by pretreatment with $5-\mathrm{HT}_{2}$ and $\alpha_{2}$-adrenergic antagonists [44].

In healthy young men, peripheral kisspeptin administration enhances prefrontal activity (as determined by functional magnetic resonance imaging [fMRI]) in response to negative-evoked visual stimuli such as images of car crashes or terminal patients [40]. This is in keeping with the role of the prefrontal area in the internalisation of safety to reduce fear and anxiety to negative stimuli [45] and is an area known to express kisspeptin receptor mRNA in humans [20]. Furthermore, peripheral kisspeptin administration to healthy men reduces negative mood in psychometric tests compared to vehicle [40] consistent with the aforementioned study in rodents [44].

These data from rodent, zebrafish, and human studies therefore implicate kisspeptin signalling in the modulation of mood and anxiety with antidepressant-like effects which may have clinical implications.

\section{Kisspeptin and Sexual Processing}

Kisspeptin is a reproductive hormone and so it seems logical that it may have effects on sexual processing beyond the HPG axis. Sexual processing is a fundamental driver of behaviour and subsequent reproduction, safeguarding the survival of most mammalian species [46]. The established involvement of several limbic and paralimbic structures including cognitive (cingulate, thalamus), emotional (amygdala, insula), motivational (putamen, precentral gyrus), and physiological (thalamus) centres in sexual processing permit the processing of a stimulus as sexual through to the autonomic activation required for sexual behaviour [47]. In healthy young heterosexual men, kisspeptin administration enhances brain activity (as determined by fMRI) in several of these limbic and paralimbic structures implicated in sexual processing, in response to visual-evoked sexual stimuli 


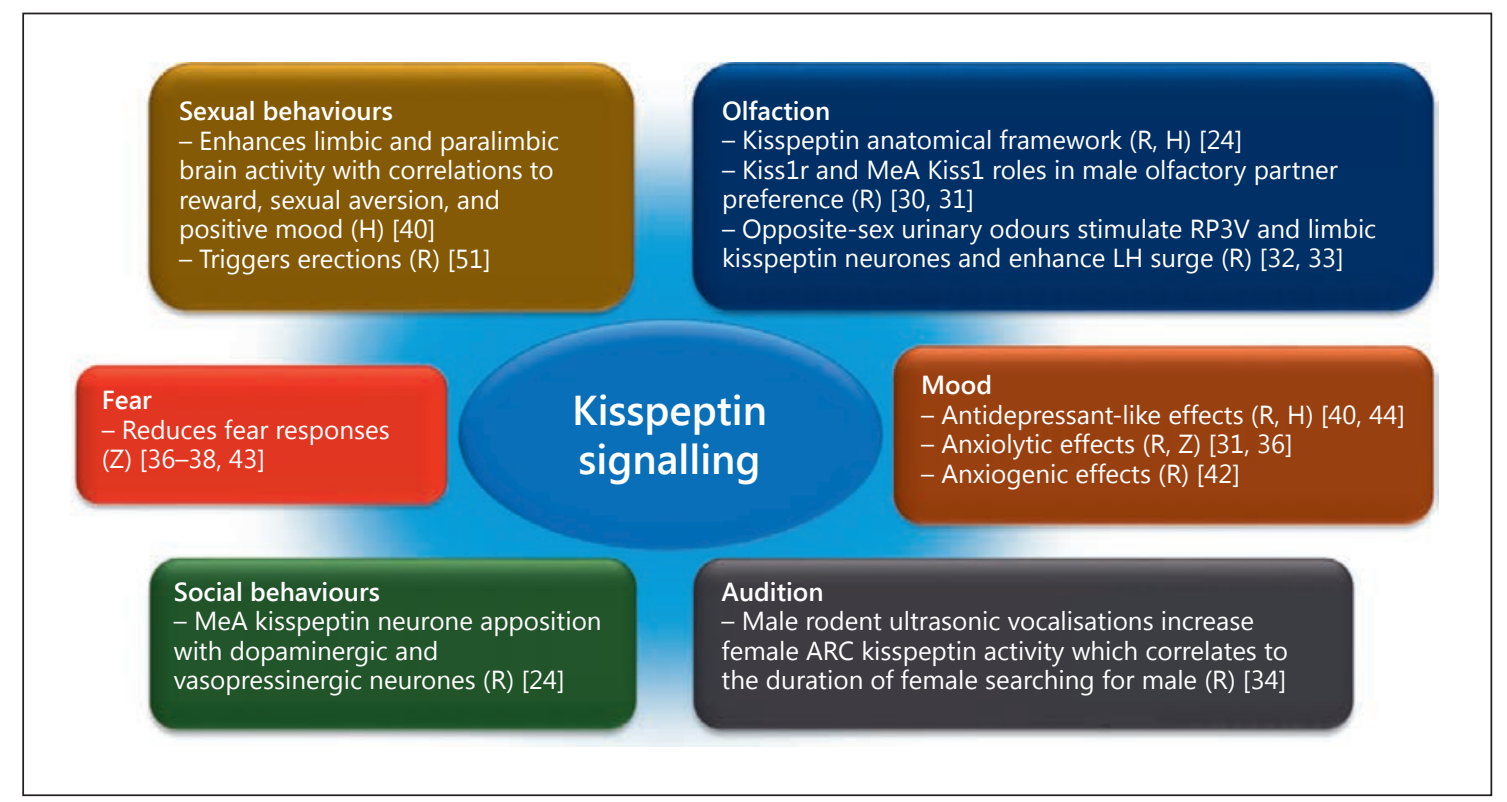

Fig. 1. Summary of currently established roles of kisspeptin signalling in facets of sexual and emotional brain processing. Species studied: rodents $(\mathrm{R})$, zebrafish $(\mathrm{Z})$, and humans $(\mathrm{H})$. Relevant references in square brackets. $\mathrm{MeA}$, medial amygdala; RP3V, rostral periventricular zone; LH, luteinising hormone; ARC, arcuate nucleus.

including the anterior and posterior cingulate and amygdala [40], and consistent with structures expressing kisspeptin and kisspeptin receptors in humans $[19,20]$ and rodents $[10,15,21,23,24]$. Furthermore in this human study, kisspeptins enhancement of activity in several of these structures of the sexual-processing network (including the cingulate, putamen, and globus pallidus) correlated with decreased aversion to sex as assessed by psychometric questionnaires.

Drive and reward are key components that govern behaviour [48] with neural substrates belonging to the mesolimbic reward and fronto-striatal-amygdala-midbrain networks $[49,50]$. Kisspeptin administration activates key components of these networks (including the hippocampus, amygdala, and cingulate) to a greater extent in men with lower baseline drive and reward traits in response to visual-evoked sexual stimuli [40]. This suggests that kisspeptin signalling could enhance reward-system activity during sexual arousal (particularly in those generally less responsive to reward), thereby triggering a desire for sexual activity and possibly subsequent reproduction.

Along these lines, a recent study in rodents demonstrated that direct bilateral injection of kisspeptin into the posterodorsal subnucleus of the medial amygdala dosedependently triggered multiple erections in male rats, an effect that was blocked by pretreatment with a kisspeptin antagonist (pep-234) [51]. Importantly, erections were not observed when kisspeptin was injected into the lateral cerebral ventricle suggesting a direct effect of kisspeptin at the site of the amygdala. In contrast, downstream androgen injection into the posterodorsal subnucleus of the medial amygdala did not result in spontaneous erections unless an oestrous female was present, demonstrating that kisspeptin can uniquely trigger erections without the presence of the oestrous female and its associated olfactory cues [52]. Collectively, these data therefore reveal a specific role for kisspeptin signalling in sexual brain processing encompassing limbic and paralimbic brain activity, sexual appetite, and erections.

In addition, the aforementioned study in heterosexual young men also identified an enhancement of limbic and paralimbic brain activity by kisspeptin administration, on viewing non-sexual couple-bonding (i.e., romantic) images [40]. This included the anterior and posterior cingulate, amygdala, thalamus, and globus pallidus, which are all implicated in romantic, maternal, and unconditional love [53-56] and consistent with structures known to be involved in kisspeptin signalling in humans $[19,20]$ and rodents $[10,15,21,23,24]$. Interestingly, kisspeptins enhanced activation of the amygdala in response to bonding images correlated with improved positive mood [40], a 
potential mechanism that may contribute to the desire to bond with a partner.

Several studies have examined the effects of reproductive hormones on libido and associated markers of sexual brain processing. A recent meta-analysis demonstrated that testosterone replacement improves libido, sexual thoughts, sexual motivation, sexual satisfaction, and nocturnal erections in most but not all studies of hypogonadal men [57]. Furthermore, testosterone supplementation has no significant overall effect on libido in eugonadal men [57] or in men complaining solely of reduced sexual desire [58]. In addition, testosterone replacement to hypogonadal men is unable to fully restore libido to that of age-matched eugonadal controls [59].

It is therefore possible, that other factors are also important in modulating libido that may include upstream kisspeptin signalling. Certainly, the expression pattern of kisspeptin and its cognate receptor in limbic and paralimbic structures would point towards this as well as the more recent studies identifying a role in sexual brain processing and erection generation. Further studies are required to determine if kisspeptin signalling could be exploited in future therapies for patients with sexual and emotional disorders.

Collectively, these data (summarised in Fig. 1) reveal a reproductive role for kisspeptin beyond the HPG axis. Kisspeptin may therefore serve to integrate sexual processing with reproductive function from reducing sexual aversion and establishing reward through to the achievement of erections and appropriate reproductive hormone release.

\section{Mechanisms}

It is interesting to speculate as to the mechanism by which kisspeptin can modulate sexual processing. In the human study above, kisspeptin had no effect on several hormones known to be involved in limbic brain processing including testosterone, oxytocin, and cortisol [40]. Furthermore, the isoform of kisspeptin used in this human study (kisspeptin-54) appears to cross the bloodbrain barrier in rodents and so may obtain direct access to the extrahypothalamic kisspeptin signalling network within the brain $[40,60]$.

The studies demonstrating antidepressant-like effects of kisspeptin and effects on fear suggest an interplay with serotonergic and adrenergic systems [37, 44], while the studies in olfaction demonstrate close appositions between kisspeptin neurones in the amygdala with vaso- pressinergic and dopaminergic afferents [24]. Other neuroendocrine systems may also be at work, as kisspeptin has established roles in nitric oxide [61], neurokinin B [62], dynorphin [63], gamma-aminobutyric acid [22], glutamate [38], and cocaine- and amphetamine-regulated transcript [64] signalling. Hence, there is a complex set of pathways that kisspeptin signalling can interact with, to bring about the aforementioned effects on emotions and sexual processing that will no doubt be a subject of future study.

\section{Conclusion and Future Directions}

The early findings of the extensive apparatus for kisspeptin signalling outside the hypothalamus $[10,15,19$, 20,23 ] have triggered a wealth of studies aiming to attach a functional relevance to this apparatus. In this review, we have detailed the state of play so far (summarised in Fig. 1). Kisspeptin signalling is required for male olfactory partner preference [30], is enhanced by opposite-sex urinary odours [32,33], modulates mate preference [31], enhances auditory-reproductive behaviour [34], dampens fear responses [36], modulates anxiety [31, 36, 42], has antidepressant-like effects $[40,44]$, and triggers erections [51]. Furthermore, in healthy heterosexual men, kisspeptin enhances limbic and paralimbic brain activity specifically in response to visual-evoked sexual and romantic stimuli and these enhancements correlate with behavioural measures including sexual aversion, reward, and mood [40]. Overall, these studies propel kisspeptin into an emerging field of study, the roles of kisspeptin in sexual and emotional processing; a field that is closely linked to kisspeptin's established role in the regulation of the HPG axis. In this way, kisspeptin may serve to integrate sexual and emotional behaviours with the HPG axis so as to modulate associated and appropriate behaviours to ultimately achieve well-being, successful reproduction, and survival of the species.

Future work will no doubt investigate the plethora of related behaviours in various species and attempt to delineate the precise neuronal pathways involved. To date, most of the data comes from male species, so it will be of great interest in the coming years to investigate if there is a sexual dimorphism in these sexual and emotional roles. Furthermore, with a better understanding of these processes, there may emerge potential therapeutic applications to aid patients with associated disorders of sexual and emotional processing. 


\section{Acknowledgements}

The Section of Endocrinology and Investigative Medicine is funded by grants from the MRC and Biotechnology and Biological Sciences Research Council, and is supported by the NIHR Imperial Biomedical Research Centre Funding Scheme. A.N.C. is supported by the NHS and BRC. W.S.D. is funded by an NIHR Research Professorship.

\section{Disclosure Statement}

The authors have declared that no conflict of interest exists.

\section{References}

1 Lee JH, Miele ME, Hicks DJ, Phillips KK, Trent JM, Weissman BE, Welch DR: KiSS-1, a novel human malignant melanoma metastasis-suppressor gene. J Natl Cancer Inst 1996;88:1731-1737.

2 de Roux N, Genin E, Carel JC, Matsuda F, Chaussain JL, Milgrom E: Hypogonadotropic hypogonadism due to loss of function of the KiSS1-derived peptide receptor GPR54. Proc Natl Acad Sci USA 2003;100:10972-10976.

3 Seminara SB, Messager S, Chatzidaki EE, Thresher RR, Acierno JS Jr, Shagoury JK, BoAbbas Y, Kuohung W, Schwinof KM, Hendrick AG, Zahn D, Dixon J, Kaiser UB, Slaugenhaupt SA, Gusella JF, O'Rahilly S, Carlton MB, Crowley WF Jr, Aparicio SA, Colledge $\mathrm{WH}$ : The GPR54 gene as a regulator of puberty. New Engl J Med 2003;349:1614-1627.

4 Topaloglu AK, Tello JA, Kotan LD, Ozbek MN, Yilmaz MB, Erdogan S, Gurbuz F, Temiz F, Millar RP, Yuksel B: Inactivating KISS1 mutation and hypogonadotropic hypogonadism. New Engl J Med 2012;366:629-635.

5 Teles MG, Bianco SD, Brito VN, Trarbach EB, Kuohung W, Xu S, Seminara SB, Mendonca BB, Kaiser UB, Latronico AC: A GPR54-activating mutation in a patient with central precocious puberty. New Engl J Med 2008;358: 709-715.

6 Silveira LG, Noel SD, Silveira-Neto AP, Abreu AP, Brito VN, Santos MG, Bianco SD, Kuohung W, Xu S, Gryngarten M, Escobar ME, Arnhold IJ, Mendonca BB, Kaiser UB, Latronico AC: Mutations of the KISS1 gene in disorders of puberty. J Clin Endocrinol Metab 2010;95:2276-2280.

7 Pinilla L, Aguilar E, Dieguez C, Millar RP, Tena-Sempere M: Kisspeptins and reproduction: physiological roles and regulatory mechanisms. Physiol Rev 2012;92:1235-1316.

8 Gottsch ML, Cunningham MJ, Smith JT, Popa SM, Acohido BV, Crowley WF, Seminara S, Clifton DK, Steiner RA: A role for kisspeptins in the regulation of gonadotropin secretion in the mouse. Endocrinology 2004; 145:4073-4077.

9 Clarkson J, Herbison AE: Postnatal development of kisspeptin neurons in mouse hypothalamus; sexual dimorphism and projections to gonadotropin-releasing hormone neurons. Endocrinology 2006;147:5817-5825.
10 Clarkson J, d'Anglemont de Tassigny X, Colledge WH, Caraty A, Herbison AE: Distribution of kisspeptin neurones in the adult female mouse brain. J Neuroendocrinol 2009; 21:673-682.

11 Irwig MS, Fraley GS, Smith JT, Acohido BV, Popa SM, Cunningham MJ, Gottsch ML, Clifton DK, Steiner RA: Kisspeptin activation of gonadotropin releasing hormone neurons and regulation of KiSS- 1 mRNA in the male rat. Neuroendocrinology 2004;80:264-272.

12 Smith JT, Popa SM, Clifton DK, Hoffman GE, Steiner RA: Kiss1 neurons in the forebrain as central processors for generating the preovulatory luteinizing hormone surge. J Neurosci 2006;26:6687-6694.

13 Kauffman AS, Gottsch ML, Roa J, Byquist AC, Crown A, Clifton DK, Hoffman GE, Steiner RA, Tena-Sempere M: Sexual differentiation of Kiss1 gene expression in the brain of the rat. Endocrinology 2007;148:1774-1783.

14 Messager S, Chatzidaki EE, Ma D, Hendrick AG, Zahn D, Dixon J, Thresher RR, Malinge I, Lomet D, Carlton MB, Colledge WH, Caraty A, Aparicio SA: Kisspeptin directly stimulates gonadotropin-releasing hormone release via $\mathrm{G}$ protein-coupled receptor 54 . Proc Natl Acad Sci USA 2005;102:1761-1766.

15 Lee DK, Nguyen T, O'Neill GP, Cheng R, Liu Y, Howard AD, Coulombe N, Tan CP, TangNguyen AT, George SR, O'Dowd BF: Discovery of a receptor related to the galanin receptors. FEBS Lett 1999;446:103-107.

16 Hrabovszky E, Ciofi P, Vida B, Horvath MC, Keller E, Caraty A, Bloom SR, Ghatei MA, Dhillo WS, Liposits Z, Kallo I: The kisspeptin system of the human hypothalamus: sexual dimorphism and relationship with gonadotropin-releasing hormone and neurokinin $\mathrm{B}$ neurons. Eur J Neurosci 2010;31:1984-1998.

17 Rometo AM, Krajewski SJ, Voytko ML, Rance NE: Hypertrophy and increased kisspeptin gene expression in the hypothalamic infundibular nucleus of postmenopausal women and ovariectomized monkeys. J Clin Endocrinol Metab 2007;92:2744-2750.

18 Smith JT, Shahab M, Pereira A, Pau KY, Clarke IJ: Hypothalamic expression of KISS1 and gonadotropin inhibitory hormone genes during the menstrual cycle of a non-human primate. Biol Reprod 2010;83:568-577.
19 Kotani M, Detheux M, Vandenbogaerde A, Communi D, Vanderwinden JM, Le Poul E, Brezillon S, Tyldesley R, Suarez-Huerta N, Vandeput F, Blanpain C, Schiffmann SN, Vassart G, Parmentier M: The metastasis suppressor gene KiSS-1 encodes kisspeptins, the natural ligands of the orphan $\mathrm{G}$ protein-coupled receptor GPR54. J Biol Chem 2001;276: 34631-34636.

20 Muir AI, Chamberlain L, Elshourbagy NA, Michalovich D, Moore DJ, Calamari A, Szekeres PG, Sarau HM, Chambers JK, Murdock P, Steplewski K, Shabon U, Miller JE, Middleton SE, Darker JG, Larminie CG, Wilson S, Bergsma DJ, Emson P, Faull R, Philpott KL, Harrison DC: AXOR12, a novel human G protein-coupled receptor, activated by the peptide KiSS-1. J Biol Chem 2001;276:28969-28975.

21 Kim J, Semaan SJ, Clifton DK, Steiner RA, Dhamija S, Kauffman AS: Regulation of Kiss1 expression by sex steroids in the amygdala of the rat and mouse. Endocrinology 2011;152: 2020-2030.

22 Di Giorgio NP, Semaan SJ, Kim J, Lopez PV, Bettler B, Libertun C, Lux-Lantos VA, Kauffman AS: Impaired GABAB receptor signaling dramatically up-regulates Kiss1 expression selectively in nonhypothalamic brain regions of adult but not prepubertal mice. Endocrinology 2014;155:1033-1044.

23 Herbison $\mathrm{AE}$, de Tassigny $\mathrm{X}$, Doran J, Colledge WH: Distribution and postnatal development of Gpr54 gene expression in mouse brain and gonadotropin-releasing hormone neurons. Endocrinology 2010;151: 312-321.

24 Pineda R, Plaisier F, Millar RP, Ludwig M: Amygdala kisspeptin neurons: putative mediators of olfactory control of the gonadotropic axis. Neuroendocrinology 2017;104: 223-238.

25 Comninos AN, Anastasovska J, Sahuri-Arisoylu M, Li X, Li S, Hu M, Jayasena CN, Ghatei MA, Bloom SR, Matthews PM, O’Byrne KT, Bell JD, Dhillo WS: Kisspeptin signaling in the amygdala modulates reproductive hormone secretion. Brain Struct Funct 2016;221: 2035-2047.

26 Catani M, Dell'acqua F, Thiebaut de Schotten $\mathrm{M}$ : A revised limbic system model for memory, emotion and behaviour. Neurosci Biobehav Rev 2013;37:1724-1737.
Emerging Roles of Kisspeptin in Sexual and Emotional Brain Processing
Neuroendocrinology 2018;106:195-202 
27 Vandenbergh JG: Pheromones and mammalian reproduction; in Neill JD (ed): Knobil and Neill's Physiology of Reproduction, 3rd ed. Elsevier, 2006, pp 2041-2058.

28 Insel TR: The challenge of translation in social neuroscience: a review of oxytocin, vasopressin, and affiliative behavior. Neuron 2010;65: 768-779.

29 Skuse DH, Gallagher L: Dopaminergic-neuropeptide interactions in the social brain. Trends Cogn Sci 2009;13:27-35.

30 Kauffman AS, Park JH, McPhie-Lalmansingh AA, Gottsch ML, Bodo C, Hohmann JG, Pavlova MN, Rohde AD, Clifton DK, Steiner RA, Rissman EF: The kisspeptin receptor GPR54 is required for sexual differentiation of the brain and behavior. J Neurosci 2007;27:88268835.

31 Adekunbi DAL, Li XF, Colledge WH, O'Byrne $\mathrm{K}$ : Kisspeptin in the posterodorsal medial amygdala modulates mate preference and anxiety in male mice. Endocr Rev 2017; 38:SAT 445.

32 Bakker J, Pierman S, Gonzalez-Martinez D: Effects of aromatase mutation (ArKO) on the sexual differentiation of kisspeptin neuronal numbers and their activation by same versus opposite sex urinary pheromones. Horm Behav 2010;57:390-395.

33 Watanabe $\mathrm{Y}$, Ikegami K, Ishigaki R, Ieda N, Uenoyama Y, Maeda KI, Tsukamura H, Inoue N: Enhancement of the LH surge by male olfactory signals is associated with AVPV Kiss 1 cell activation in female rats. J Neuroendocrinol 2017;29:e12505.

34 Asaba A, Osakada T, Touhara K, Kato M, Mogi K, Kikusui T: Male mice ultrasonic vocalizations enhance female sexual approach and hypothalamic kisspeptin neuron activity. Horm Behav 2017;94:53-60.

35 Speedie N, Gerlai R: Alarm substance induced behavioral responses in zebrafish (Danio rerio). Behav Brain Res 2008;188:168-177.

36 Ogawa S, Nathan FM, Parhar IS: Habenular kisspeptin modulates fear in the zebrafish. Proc Natl Acad Sci USA 2014;111:3841-3846.

37 Nathan FM, Ogawa S, Parhar IS: Kisspeptin1 modulates odorant-evoked fear response via two serotonin receptor subtypes (5-HT1A and 5-HT2) in zebrafish. J Neurochem 2015; 133:870-878.

38 Nathan FM, Ogawa S, Parhar IS: Neuronal connectivity between habenular glutamatekisspeptin 1 co-expressing neurons and the raphe 5-HT system. J Neurochem 2015;135: 814-829.

39 Rao YS, Mott NN, Pak TR: Effects of kisspeptin on parameters of the HPA axis. Endocrine 2011;39:220-228.
40 Comninos AN, Wall MB, Demetriou L, Shah AJ, Clarke SA, Narayanaswamy S, Nesbitt A, Izzi-Engbeaya C, Prague JK, Abbara A, Ratnasabapathy R, Salem V, Nijher GM, Jayasena CN, Tanner M, Bassett P, Mehta A, Rabiner EA, Honigsperger C, Silva MR, Brandtzaeg OK, Lundanes E, Wilson SR, Brown RC, Thomas SA, Bloom SR, Dhillo WS: Kisspeptin modulates sexual and emotional brain processing in humans. J Clin Invest 2017;127: 709-719.

41 Kinsey-Jones JS, Li XF, Knox AM, Wilkinson ES, Zhu XL, Chaudhary AA, Milligan SR, Lightman SL, O’Byrne KT: Down-regulation of hypothalamic kisspeptin and its receptor, Kiss1r, mRNA expression is associated with stress-induced suppression of luteinising hormone secretion in the female rat. J Neuroendocrinol 2009;21:20-29.

42 Csabafi K, Jaszberenyi M, Bagosi Z, Liptak N, Telegdy G: Effects of kisspeptin-13 on the hypothalamic-pituitary-adrenal axis, thermoregulation, anxiety and locomotor activity in rats. Behav Brain Res 2013;241:56-61.

43 Ogawa S, Ng KW, Ramadasan PN, Nathan FM, Parhar IS: Habenular Kiss1 neurons modulate the serotonergic system in the brain of zebrafish. Endocrinology 2012;153:23982407.

44 Tanaka M, Csabafi K, Telegdy G: Neurotransmissions of antidepressant-like effects of kisspeptin-13. Regul Pept 2013;180:1-4.

45 Silvers JA, Wager TD, Weber J, Ochsner KN: The neural bases of uninstructed negative emotion modulation. Soc Cogn Affect Neurosci 2015;10:10-18.

46 Benagiano G, Carrara S, Filippi V: Sex and reproduction: an evolving relationship. Hum Reprod Update 2010;16:96-107.

47 Stoleru S, Gregoire MC, Gerard D, Decety J, Lafarge E, Cinotti L, Lavenne F, Le Bars D, Vernet-Maury E, Rada H, Collet C, Mazoyer B, Forest MG, Magnin F, Spira A, Comar D: Neuroanatomical correlates of visually evoked sexual arousal in human males. Arch Sex Behav 1999;28:1-21.

48 Carver CS, White TL: Behavioral inhibition, behavioral activation, and affective responses to impending reward and punishment: the BIS/BAS scales. J Pers Soc Psychol 1994;67: 319-333.

49 Costumero V, Barros-Loscertales A, Bustamante JC, Ventura-Campos N, Fuentes P, Rosell-Negre P, Avila C: Reward sensitivity is associated with brain activity during erotic stimulus processing. PLoS One 2013; 8:e66940.

50 Beaver JD, Lawrence AD, van Ditzhuijzen J, Davis MH, Woods A, Calder AJ: Individual differences in reward drive predict neural responses to images of food. J Neurosci 2006;26: 5160-5166.
51 Gresham R, Li S, Adekunbi DA, Hu M, Li XF, O'Byrne KT: Kisspeptin in the medial amygdala and sexual behavior in male rats. Neurosci Lett 2016;627:13-17.

52 Bialy M, Sachs BD: Androgen implants in medial amygdala briefly maintain noncontact erection in castrated male rats. Horm Behav 2002;42:345-355.

53 Acevedo BP, Aron A, Fisher HE, Brown LL: Neural correlates of long-term intense romantic love. Soc Cogn Affect Neurosci 2012; 7:145-159.

54 Bartels A, Zeki S: The neural correlates of maternal and romantic love. Neuroimage 2004; 21:1155-1166.

55 Wan MW, Downey D, Strachan H, Elliott R, Williams SR, Abel KM: The neural basis of maternal bonding. PLoS One 2014;9:e88436.

56 Beauregard M, Courtemanche J, Paquette V, St-Pierre EL: The neural basis of unconditional love. Psychiatry Res 2009;172:93-98.

57 Corona G, Isidori AM, Buvat J, Aversa A, Rastrelli G, Hackett G, Rochira V, Sforza A, Lenzi A, Mannucci E, Maggi M: Testosterone supplementation and sexual function: a metaanalysis study. J Sex Med 2014;11:1577-1592.

58 O'Carroll R, Bancroft J: Testosterone therapy for low sexual interest and erectile dysfunction in men: a controlled study. Br J Psychiatry 1984;145:146-151.

59 Ramasamy R, Wilken N, Scovell JM, Lipshultz LI: Effect of testosterone supplementation on symptoms in men with hypogonadism. Eur Urol 2015;67:176-177.

60 d'Anglemont de Tassigny X, Jayasena C, Murphy KG, Dhillo WS, Colledge WH: Mechanistic insights into the more potent effect of KP-54 compared to KP-10 in vivo. PLoS One 2017;12:e0176821.

61 Hanchate NK, Parkash J, Bellefontaine N, Mazur D, Colledge WH, d'Anglemont de Tassigny X, Prevot V: Kisspeptin-GPR54 signaling in mouse NO-synthesizing neurons participates in the hypothalamic control of ovulation. J Neurosci 2012;32:932-945.

62 Fergani C, Navarro V: Expanding the role of tachykinins in the neuroendocrine control of reproduction. Reproduction 2016, pii: REP16-0378.

63 Millar RP: New developments in kisspeptin, neurokinin $\mathrm{B}$ and dynorphin A regulation of gonadotropin-releasing hormone pulsatile secretion. Neuroendocrinology 2014;99:5-6.

64 True C, Verma S, Grove KL, Smith MS: Cocaine- and amphetamine-regulated transcript is a potent stimulator of $\mathrm{GnRH}$ and kisspeptin cells and may contribute to negative energy balance-induced reproductive inhibition in females. Endocrinology 2013;154:2821-2832. 